\title{
PENGARUH KOMITMEN DAN KEPUASAN KERJA DOKTER SPESIALIS TERHADAP PENGISIAN REKAM MEDIS DI RUANG RAWAT INAP RUMAH SAKIT PERMATA BUNDA MEDAN TAHUN 2018
}

\author{
The Influence Of The Commitment And Work Satisfaction Of Specialists Doctors On Filling \\ Of Medical Records In The Inpatient Room At Permata Bunda Hospital In Medan In 2018
}

\author{
Harry Chrismanda ${ }^{1}$, Zulfendri Zulfendri ${ }^{2}$, Destanul Aulia ${ }^{3}$ \\ ${ }^{1,2,3}$ Fakultas Kesehatan Masyarakat Universitas Sumatera Utara
}

\begin{abstract}
Abstrak
Rekam medis merupakan salah satu unsur utama didalam sistem pelayanan kesehatan Rumah Sakit yang baik dan bermutu. Ketidaklengkapan dokumen rekam medis menjadi salah satu masalah yang masih belum teratasi sampai saat ini. Pada survei awal yang dilakukan di ruang rawat inap Rumah Sakit Permata Bunda, masih didapati ketidaklengkapan dokumen rekam medis oleh dokter spesialis. Tujuan penelitian adalah untuk mengetahui pengaruh komitmen dokter spesialis terhadap pengisian rekam medis di ruang rawat inap Rumah Sakit Permata Bunda Kota Medan. Jenis penelitian ini adalah survei explanatory research dengan desain cross sectional. Lokus penelitian ini di Rumah Sakit Permata Bunda Kota Medan, pada bulan Juli tahun 2018 sampai dengan selesai. Keseluruhan jumlah populasi juga merupakan sampel penelitian yaitu sebanyak 41 dokter spesialis. Metode analisis data menggunakan regresi logistik. Hasil penelitian menunjukkan variabel komitmen dokter berpengaruh secara signifikan terhadap pengisian rekam medis. Semakin berkomitmen seorang dokter spesialis maka akan meningkatkan pengisian rekam medis dibandingkan dengan dokter spesialis yang tidak berkomitmen. Disarankan kepada manajemen rumah sakit agar memberikan reward kepada dokter spesialis yang meluangkan waktu lebih dalam mengisi rekam medis.
\end{abstract}

Kata Kunci: Komitmen, Dokter Spesialis, Rekam Medis

\begin{abstract}
Medical records is one of the main factors in the health service system of a good and excellent hospital. Incomplete documents of medical record become a problem that is not resolved yet until the present. In the initial survey carried out in the inpatient room of the Permata Bunda Hospital, still found incomplete medical record document by spescialist doctors. The objective of the research was to discover the influence of commitment specialist doctors on the performance of medical records in the inpatient room at Permata Bunda Hospital in Medan. This is an explanatory survey research with cross sectional design. The locus of the research was at Permata Bunda Hospital in Medan, starting from July 2018 until it was done. The whole population was taken as the research samples 41 specialist doctors. The data were analyzed by applying logistic regression method. The results of the research demonstrated that commitment of the specialist doctors had significant influence of the performance of the medical records. More committed specialist doctors will improve the performance of the medical records compared to those with less commitment. It is recommended to hospital management to give reward to specialist doctors who spend more time filling of medical record.

Keywords: Commitment, Specialist Doctors, Medical Record
\end{abstract}

Korespondensi : Harry Chrismanda

Email : harrychrismanda007@gmail.com

\section{PENDAHULUAN}

Rumah sakit merupakan tempat penyelenggaraan pelayanan kesehatan yang melibatkan banyak komponen-komponen yang mendukung dengan tujuan demi terciptanya sistem pelayanan kesehatan optimal di rumah sakit dan menghasilkan standar mutu pelayanan kesehatan yang tinggi (1). Salah satu unsur utama dalam sistem pelayanan kesehatan yang baik dan bermutu adalah tersedianya penyelenggaraan pelayanan rekam medis. Penyelenggaraan rekam medis ini harus dilakukan dengan kualitasnya yang terpelihara dengan baik. Dalam penyelenggaraan praktik kedokteran, setiap dokter dan dokter gigi wajib merujuk kepada standar, pedoman dan prosedur yang sudah berlaku (2). Rekam medis yang bermutu adalah rekam medis yang memenuhi indikator-indikator mutu rekam medis yaitu kelengkapan isian, keakuratan dan tepat waktu (3). Kelengkapan pengisian rekam medis yang dimaksud adalah rekam medis yang telah diisi secara lengkap oleh dokter dalam waktu $\leq 24$ jam setelah pasien selesai mendapatkan pelayanan rawat jalan atau setelah pasien rawat inap diputuskan untuk pulang. Ketidaklengkapan dokumen rekam medis menjadi salah satu masalah yang masih belum teratasi sampai saat ini. Hal ini dikarenakan dokter dan dokter gigi kurang menyadari secara penuh akan tujuan, manfaat dan kepentingan dari rekam medis tersebut (4). Survei awal yang dilakukan oleh peneliti, didapati bahwa Rumah Sakit Permata Bunda masih memiliki kekurangan. Kekurangan yang dimaksud adalah mengenai kelengkapan pengisian atau 
pendokumentasian rekam medis. Peneliti mengobservasi 50 rekam medis pasien di ruang rawat inap sebagai sampel, didapatkan kelengkapan berkas sebanyak 18 dokumen atau 36\% lembar resume masih belum terisi dengan baik dan masih terdapat kekosongan. Keakuratan berkas rekam medis sebanyak 17 dokumen atau 34\%. Berbeda dengan rawat inap, hasil observasi untuk rekam medis rawat jalan sudah terpenuhi sesuai dengan standar yang berlaku. Baik ketepatan pengisiannya maupun pengembaliannya ke instalasi rekam medis. Hal ini dikarenakan pelayanan rawat jalan dilakukan pada suatu waktu dan tidak memerlukan pemeriksaan serta observasi lebih lanjut seperti yang dilakukan di pelayanan rawat inap (5). Hasil pengamatan peneliti di Rumah Sakit Permata Bunda Kota Medan, beberapa dokter spesialis menunda-nunda pengisian lembar resume rekam medis setelah pasien dinyatakan pulang, sehingga lembar resume rekam medis tersebut tidak terisi atau tidak dilengkapi sampai melebihi batas waktu sesuai standar yang telah ditentukan. Penundaan pengisian lembar resume rekam medis tersebut disebabkan oleh keterbatasan waktu dokter spesialis tersebut untuk melayani pasien. Selain itu sering kali saran kepulangan pasien dilakukan melalui telepon, tanpa dilihat terlebih dahulu oleh dokter spesialis yang merawat pasien tersebut (6). Dokter spesialis harus menyadari akan pentingnya pendokumentasian rekam medis dan dapat mengatur waktu sebaik mungkin didalam menjalani seluruh kewajibannya terhadap pasien di unit rawat jalan maupun rawat inap serta pasien yang membutuhkan tindakan pembedahan. Jika tidak dapat mengaturnya dengan baik maka dokter spesialis tidak dapat bekerja dengan standar pelayanan medis, yang salah satunya ialah mengisi dan melengkapi dokumen rekam medis segera setelah pasien dinyatakan pulang (7). Oleh karena itu komitmen dari dokter spesialis sangat diperlukan, sehingga segala permasalahan yang timbul diatas tidak menjadi penghambat bagi dokter spesialis dalam memberikan pelayanan kesehatan. Komitmen yang tinggi tersebut memungkinkan dokter spesialis untuk tetap bertahan dengan memberikan semua tenaga, potensi, dan pikiran demi peningkatan mutu pelayanan kesehatan dan kemajuan rumah sakit (8). Fenomena lain yang terjadi di Rumah Sakit Permata Bunda Kota Medan ialah pemberian jasa medis yang sering tertunda dalam jangka waktu yang bervariasi kepada setiap dokter spesialis. Kisaran waktu penundaan pemberian jasa medis tersebut antara satu sampai dengan tiga bulan yang tidak dibayarkan kepada dokter spesialis. Jasa medis yang diberikan kepada dokter spesialis tidak sesuai dengan acuan tarif yang diterbitkan oleh PB IDI (Pengurus Besar Ikatan Dokter Indonesia), hal ini berhubungan dengan kepuasan kerja yang menyebabkan dokter spesialis kurang memperhatikan, menyadari dan menjalankan pengisian dokumen rekam medis sesuai standar yang berlaku (9). Berdasarkan penelitian yang dilakukan di Rumah Sakit Muhammadiyah Yogyakarta oleh Rosalina (2013) mengenai analisis pengaruh faktorfaktor kepuasan kerja terhadap kinerja pengisian rekam medis. Penelitian ini menunjukkan kepuasan pada pekerjaan terbukti berpengaruh signifikan terhadap kinerja dokter dalam pengisian rekam medis pasien rawat inap. Kepuasan yang dimaksud adalah pada gaji atau tindakan medis, pimpinan, pada rekan kerja dan kesempatan promosi atau peningkatan karir terbukti berpengaruh signifikan terhadap kinerja dokter dalam pengisian rekam medis pasien rawat inap (10). Pekerja yang memiliki kepuasan akan bekerja dengan lebih baik lagi, penuh dengan semangat, bersifat proaktif, dan dapat berprestasi lebih baik daripada pekerja yang tidak mendapatkan kepuasan kerja (11). Kepuasan kerja memiliki keterkaitan dengan tugas-tugas yang menarik bagi pekerja, tingkat tanggungjawab seseorang di dalam melakukan pekerjaannya dan bagaimana seorang pekerja mendapatkan kesempatan untuk mempelajari hal-hal yang baru di dalam pekerjaannya. Hal-hal tersebut tentunya akan berkontribusi untuk kemajuan dan keberhasilan tujuan dari suatu pekerjaan yang dilakukan oleh seorang pekerja (12). Manusia di dalam melakukan kewajiban atau pekerjaannya dapat dipengaruhi oleh maintenance factors. Maintenance factors merupakan faktor-faktor yang terlibat atau berhubungan dengan pemenuhan jasmani manusia yang terdiri dari gaji, kondisi kerja, kebijakan dan administrasi organisasi, interpersonal relation dan kualitas supervisi. 
Faktor-faktor ini harus dijaga agar tercipta peningkatan kepuasan dalam bekerja. Gaji dapat lebih banyak menyebabkan ketidakpuasan di dalam melakukan pekerjaan. Tidak jarang orang mengekspresikan kepuasan dengan sejumlah uang yang diperoleh karena pekerjaannya (13). Berdasarkan penelitian yang dilakukan di Rumah Sakit Umum Daerah (RSUD) Sunan Kalijaga oleh Nani (2011) menerangkan bahwa faktor manajemen yang berpengaruh terhadap pengisian rekam medis adalah komitmen dokter. Variabel yang berhubungan dengan komitmen dokter dalam mengisi dokumen rekam medis adalah kejelasan jasa medis, pembuatan keputusan pemimpin, tindakan dukungan pemimpin dan kondisi lingkungan kerja (14). Pekerja yang memiliki komitmen yang tinggi akan memberikan dan menyerahkan seluruh kemampuan, keterampilan dan pikiran yang dimilikinya. Sehingga komitmen organisasional memiliki pengaruh positif dan signifikan terhadap kinerja pekerja atau karyawan. Terdapat hubungan yang positif antara komitmen afektif dan normatif dengan kinerja. Sedangkan continuance commitment atau komitmen kontinuans memiliki hubungan yang negatif dengan kinerja (15). Berdasarkan pemaparan diatas, peneliti tertarik untuk melakukan penelitian tentang "pengaruh komitmen dokter spesialis terhadap pengisian rekam medis di ruang rawat inap Rumah Sakit Permata Bunda Kota Medan".

\section{METODE}

Jenis penelitian ini adalah penelitian survei dengan tipe explanatory research dengan desain penelitian cross sectional. Penelitian ini dilaksanakan di Rumah Sakit Permata Bunda Kota Medan yang berlokasi di Jalan Sisingamangaraja no.7 Kota Medan, dimulai dari bulan Juli tahun 2018 sampai dengan selesai. Populasi dalam penelitian ini adalah dokter spesialis yang berpraktik di Rumah Sakit Permata Bunda Kota Medan. Keseluruhan jumlah populasi juga merupakan sampel penelitian ini yaitu sebanyak 41 dokter spesialis. Metode pengumpulan data dalam penelitian ini melalui data primer dan sekunder dengan kuesioner dan wawancara. Adapun metode analisis data dalam penelitian ini adalah dengan regresi logistik.

\section{HASIL PENELITIAN}

Distribusi frekuensi responden dapat diketahui bahwa dari 41 responden yang diamati, mayoritas responden berjenis kelamin laki-laki yaitu ada sebanyak 28 orang $(68,3 \%)$, berumur pada rentang 46-55 tahun yaitu ada sebanyak 14 orang (34,2\%), berstatus sudah menikah yaitu ada sebanyak 41 orang $(100 \%)$, status kepegawaian adalah PNS yaitu ada sebanyak 34 orang $(82,9 \%)$, dengan lama praktik >3 tahun yaitu ada sebanyak 25 orang $(61,0 \%)$, dengan jalur bekerja lewat lamaran yaitu ada sebanyak 38 orang $(92,7 \%)$, dan jenis spesialistik anak dan THT yang masing-masing ada sebanyak 5 orang $(12,2 \%)$.

Tabel 1. Tabulasi Silang Komitmen Dokter Spesialis dengan Pengisian Rekam Medis

\begin{tabular}{|c|c|c|c|c|c|c|}
\hline \multirow{3}{*}{ Komitmen } & \multicolumn{4}{|c|}{ Pengisian Rekam Medis } & \multirow{2}{*}{\multicolumn{2}{|c|}{ Total }} \\
\hline & \multicolumn{2}{|c|}{ Baik } & \multicolumn{2}{|c|}{ Tidak Baik } & & \\
\hline & $\mathbf{f}$ & $\%$ & f & $\%$ & $\mathbf{N}$ & $\%$ \\
\hline Berkomitmen & 12 & 36,4 & 21 & 63,6 & 33 & 100 \\
\hline Tidak berkomitmen & 0 & 0 & 8 & 100 & 8 & 100 \\
\hline Total & 12 & 29,3 & 29 & $\mathbf{7 0 , 7}$ & 41 & 100 \\
\hline
\end{tabular}

Tabel 2. Tabulasi Silang Komitmen Dokter Spesialis dengan Pengisian Rekam Medis

\begin{tabular}{|c|c|c|c|c|c|c|}
\hline \multirow{3}{*}{ Kepuasan Kerja } & \multicolumn{4}{|c|}{ Performance Rekam Medis } & \multirow{2}{*}{\multicolumn{2}{|c|}{ Total }} \\
\hline & \multicolumn{2}{|c|}{ Baik } & \multicolumn{2}{|c|}{ Tidak Baik } & & \\
\hline & f & $\%$ & $\mathbf{f}$ & $\%$ & $\mathbf{N}$ & $\%$ \\
\hline Puas & 9 & 25,7 & 26 & 74,3 & 35 & 100,0 \\
\hline Tidak Puas & 3 & 50,0 & 3 & 50,0 & 6 & 100,0 \\
\hline Total & 12 & 29,3 & 29 & 70,7 & 41 & 100,0 \\
\hline
\end{tabular}


Tabel 3. Hubungan Komitmen dan Kepuasan Kerja Dokter Spesialis dengan Pengisian Rekam Medis

\begin{tabular}{lc}
\hline Variabel & p value \\
\hline Komitmen & 0,023 \\
Kepuasan Kerja & 0,145 \\
\hline
\end{tabular}

Tabel 5. Pengaruh Komitmen Dokter Spesialis terhadap Pengisian Rekam Medis

\begin{tabular}{lccccccc}
\hline Variabel & B & S.E & Wald & Df & $\begin{array}{c}\text { p } \\
\text { value }\end{array}$ & $\begin{array}{c}\text { Exp } \\
(\mathbf{B})\end{array}$ & $\begin{array}{c}\text { 95 C.I.For } \\
\text { EXP (B) }\end{array}$ \\
\hline Komitmen & 1,059 & 0,418 & 4,734 & 1 & 0,030 & 2,562 & $1,267-5,438$ \\
\hline
\end{tabular}

\section{PEMBAHASAN}

Berdasarkan hasil analisis dapat diketahui bahwa variabel komitmen memiliki nilai $p$ value 0.023. Menurut Dahlan (2014), variabel yang nilai $p$ value $<0,05$ memiliki hubungan atau saling berinteraksi (16). Maka dapat disimpulkan bahwa variabel independen komitmen berhubungan secara signifikan dengan pengisian rekam medis. Langkah terakhir akan terlihat nilai $\exp$ (B) yang menunjukkan semakin besar nilainya maka semakin besar pengaruh variabel bebas terhadap variabel terikat. Pada komitmen dokter spesialis nilai koefisien regresi $(\beta)$ bernilai positif, artinya semakin berkomitmen seorang dokter spesialis maka berpeluang pengisian rekam medisnya 2,562 kali lebih baik dibandingkan dengan dokter spesialis yang tidak berkomitmen. Dimensi komitmen terdiri atas komitmen afektif (affective commitment). Komitmen afektif ini melibatkan rasa memiliki di dalam organisasi. Komitmen ini mengikat para pekerja. Pekerja yang sudah lama berada dalam suatu organisasi, jika mendapatkan reward seharusnya memiliki komitmen yang tinggi. Tanggungjawab dan rasa memiliki terhadap pekerjaannya, dapat membuatnya untuk tetap tinggal di dalam organisasi tersebut. Komitmen berikutnya adalah Komitmen kontinuans (continuance commitment). Disini faktor rasional yang menentukan dalam komitmen pekerja. Pekerja akan berfikir untuk memperhitungkan besar kecilnya pembiayaan dan resiko jika meninggalkan organisasi. Dimensi komitmen lainnya adalah komitmen normatif (normative commitment). Komitmen ini lebih menggambarkan dedikasi dan keterkaitan perasaan seorang pekerja untuk bekerja dan tetap berada pada organisasinya. Seseorang akan tetap setia karena perasaannya memang mengatakan demikian. Komitmen ini merupakan komitmen yang paling tinggi. Perasaan sangat mendominasi dalam komitmen ini, dan akan menimbulkan motivasi yang besar terhadap pekerjaan (17). Dari hasil penelitian didapati bahwa dokter spesialis tidak setuju jika harus mengorbankan seluruh waktu demi rumah sakit. Hal ini disebabkan karena dokter spesialis masih sulit untuk dapat membagi waktu antara untuk rumah sakit, untuk istirahat ataupun melakukan kegiatan lain selain dari kewajiban profesinya. Dokter spesialis akan tetap mengorbankan seluruh pikiran dan tenaganya untuk rumah sakit, tetapi untuk mengorbankan waktu akan sulit. Ini berkaitan dengan komitmen normatif. Komitmen normatif merupakan komitmen yang paling tinggi dibandingkan dengan komitmen afektif dan kontinuans. Komitmen normatif bersifat mengikat sangat kuat agar dokter spesialis dapat meningkatkan motivasi didalam melakukan kewajiban profesinya. Penelitian lain yang dilakukan oleh Septia (2013) di RSUD M. Djamil Padang menunjukkan bahwa komitmen merupakan hal yang utama dalam keberhasilan sebuah organisasi. Komitmen dokter spesialis merupakan salah satu faktor yang penting untuk memberikan dan menghasilkan pelayanan yang bermutu serta optimal di rumah sakit (18). Penelitian pendukung lainnya adalah penelitian yang dilakukan di RSUD Ulin Banjarmasin oleh Agustina (2013) menunjukkan bahwa ada pengaruh komitmen organisasional, motivasi intrinsik dan motivasi ekstrinsik terhadap kinerja dokter baik secara parsial maupun secara simultan. Motivasi intrinsik mempunyai pengaruh yang paling besar terhadap kinerja dokter, disusul oleh motivasi ekstrinsik dan komitmen organisasional (19). Sudjarwanto (2017) mengatakan terdapat berbagai faktor yang dapat mempengaruhi ketidaklengkapan dokumen rekam medis tersebut, yaitu faktor individu dan faktor organisasi. Penelitian ini 
bertujuan untuk mengidentifikasi karakteristik petugas dan menganalisis kinerja dari dokter serta perawat dalam kelengkapan pengisian dokumen rekam medis. Komitmen dapat diraih jika orang yang bekerja didalam organisasi tersebut memiliki kesadaran tentang hak dan kewajibannya didalam suatu organisasi. Penerimaan hasil dari tujuan organisasi tersebut merupakan hasil kerja seluruh anggota yang berada didalam organisasi dan secara bersamaan serta menyeluruh (20).

\section{KESIMPULAN DAN SARAN}

Mengorbankan waktu terhadap Rumah sakit merupakan indikator dari komitmen yang paling mempengaruhi terhadap pengisian rekam medis, sehingga dapat juga disimpulkan bahwa komitmen normatif lebih berpengaruh dibandingkan dengan komitmen afektif dan kontinuans. Pengisian rekam medis membutuhkan kesedian dokter spesialis untuk dapat meluangkan waktunya, sehingga rekam medis yang harus diisi memiliki kelengkapan, keakuratan dan ketepatan waktu yang baik. Jadi dapat disimpulkan semakin baik komitmen dokter spesialis makan akan semakin baik pula pengisian rekam medisnya. Disarankan kepada pihak manajemen rumah sakit harus dapat memperhatikan hal-hal lain yang dapat meningkatkan komitmen dokter spesialis tersebut, seperti memberikan reward bagi dokter spesialis yang dapat meluangkan waktu lebih untuk rumah sakit terutama didalam melengkapi pengisian rekam medis dan memberikan punishment bagi yang tidak mengisinya.

\section{DAFTAR PUSTAKA}

1. Nurfadhilah, 2015. Analisis Hubungan Kelengkapan Pengisian Resume Medis Terhadap Kesesuaian Standar Tarif INACBG'S Instalasi Rawat Inap Teratai RSUP Fatmawati Jakarta. Jurnal Kedokteran dan Kesehatan, Vol. 13, No. 1, 2017.

2. Pemerintah Indonesia. 2004. Undangundang Republik Indonesia Nomor 29 Tahun 2004 tentang Praktik Kedokteran. Lembaran RI tahun 2004 No. 29. Jakarta: Sekretariat Negara.

3. Hatta, Gemala. 2013. Pedoman Manajemen Informasi Kesehatan di
Sarana Pelayanan Kesehatan.

Universitas Indonesia. Jakarta.

4. Konsil Kedokteran Indonesia (Indonesian Medical Council), 2006, Manual Rekam Medis, Kelompok Kerja Penyusunan Manual Rekam Medis, Jakarta.

5. Agni, 2014. Pengembangan Alur Pasien dan Rekam Medis Sebagai Optimalisasi Sistem Informasi Rekam Medis. Jurnal Kedokteran Brawijaya, Vol. 28, No. 2, 2015.

6. Baharuddin, 2017. Tinjauan Etik Regulasi Jam Kerja Dokter di Indonesia. JEKI. Vol. 1, No. 1, 2017.

7. Sarwanti, 2014. Analisis Hubungan Perilaku Dokter Spesialis Surgical Dalam Pengisian Kelengkapan Resume Medik Pasien Rawat Inap di RSUP Fatmawati Tahun 2014. Fakultas Kesehatan Masyarakat Depok: Universitas Indonesia.

8. Nazri, 2016. Pengaruh Beban Kerja dan Komitmen Tenaga Kesehatan Terhadap Kepuasan Pasien Pada Puskesmas Tanjung Beringin Kabupaten Serdang Bedagai. Fakultas Kesehatan Masyarakat: Universitas Sumatera Utara.

9. Winda, 2016. Faktor-faktor yang Berhubungan Dengan Kepuasan Kerja Dokter Spesialis di Instalasi Rawat Jalan RSUP. DR. R. D. Kandou Manado. Program Pasca Sarjana: Universitas Sam Ratulangi Manado.

10. Rosalina, 2013. Analisis Pengaruh Faktor-Faktor Kepuasan Kerja Terhadap Kinerja Pengisian Rekam Medis Rawat Jalan. Program Studi Magister Manajemen: Universitas Diponegoro.

11. Handoko TH. 2014. Manajemen Personalia dan Sumber Daya Manusia. Yogyakarta.

12. Luthans, F., 2014. Perilaku Organisasi, Edisi 10. Yogyakarta.

13. Mangkunegara, 2014. Manajemen Sumeber Daya Manusia. Remaja Rosda Karya, Bandung.

14. Nani, 2011. Analisis Pengaruh FaktorFaktor Manajemen Terhadap Komitmen Dokter dalam Pengisian Dokumen Rekam Medis Rawat Inap di RSUD Sunan Kalijaga Kabupaten Demak. Fakultas Kesehatan Masyarakat: Universitas Diponegoro. 
15. Syauta, Eka, Margono dan Solimun. 2012. The Influence of Organizational Culture, Organizational Commitment to Job Satisfication and Employee Performance. Journal Business and Management Invention. Vol. 01. Reitreved from Emerald Insight.

16. Dahlan, Sopiyudin. 2014. Statistik Untuk Kedokteran dan Kesehatan Edisi 6. Salemba Medika Jakarta.

17. Robbins S, Timothy A. 2014. Perilaku Organisasi. Gramedia Jakarta.

18. Septia ED, 2013. Hubungan Karakteristik Manajerial dengan
Komitmen Dokter Spesialis Di Instalasi Rawat Jalan di RSUD Dr.M. Djamil Padang.Universitas Andalas Padang.

19. Agustina, 2013. Pengaruh Komitmen Organisasional, Motivasi Intrinsik dan Motivasi Ekstrinsik Terhadap Kinerja Dokter di RSUD Ulin Banjarmasin. Jurnal Universitas Lambung Mangkurat. Vo. 1, No. 3, 2013.

20. Sudjarwanto, 2017. Analisis Peningkatan Kelengkapan Pengisian Rekam Medis Di Rumah Sakit Asyiyah Bojonegoro Dengan Pendekatan Force Field Analysis. Universitas Airlangga. 